\title{
Physicians' experience adopting the electronic transfer of care communication tool: barriers and opportunities
}

This article was published in the following Dove Press journal:

Journal of Multidisciplinary Healthcare

14 January 2015

Number of times this article has been viewed

\author{
Chloe de Grood \\ Katherine Eso \\ Maria Jose Santana \\ Department of Community Health \\ Sciences, W2IC Research and \\ Innovation Centre, Institute of Public \\ Health, University of Calgary, Calgary, \\ $A B$, Canada
}

Purpose: The purpose of this study was to assess physicians' perceptions on a newly developed electronic transfer of care (e-TOC) communication tool and identify barriers and opportunities toward its adoption.

Participants and methods: The study was conducted in a tertiary care teaching center as part of a randomized controlled trial assessing the efficacy of an e-TOC communication tool. The e-TOC technology was developed through iterative consultation with stakeholders. This e-TOC summary was populated by acute care physicians (AcPs) and communicated electronically to community care physicians ( $\mathrm{CcPs})$. The AcPs consisted of attending physicians, resident trainees, and medical students rotating through the Medical Teaching Unit. The CcPs were health care providers caring for patients discharged from hospital to the community. AcPs and CcPs completed validated surveys assessing their experience with the newly developed e-TOC tool. Free text questions were added to gather general comments from both groups of physicians. Units of analysis were individual physicians. Data from the surveys were analyzed using mixed methods.

Results: AcPs completed 138 linked pre- and post-rotation surveys. At post-rotation, each AcP completed an average of six e-TOC summaries, taking an average of 37 minutes per e-TOC summary. Over $100 \mathrm{CcPs}$ assessed the quality of the TOC summaries, with an overall rating of 8.3 (standard deviation: 1.48; on a scale of 1-10). Thematic analyses revealed barriers and opportunities encountered by physicians toward the adoption of the e-TOC tool. While the AcPs highlighted issues with timeliness, usability, and presentation, the CcPs identified barriers accessing the web-based TOC summaries, emphasizing that the summaries were timely and the quality of information supported continuity of care.

Conclusion: Despite the barriers identified by both groups of physicians, the e-TOC communication tool was well received. Our experience can serve as a template for other health research teams considering the implementation of e-health technologies into health care systems.

Keywords: e-health, transition, summary, informatics

\section{Introduction}

Ensuring high-quality patient care is a major objective in the delivery of health care. Communication between acute care physicians (AcPs) and community care physicians (CcPs) is paramount to the delivery of high quality care, especially as complex patients transition from the hospital to the community. Traditionally, this communication is facilitated via the transfer of care (TOC) summary. ${ }^{1}$ High-quality TOC summaries should be delivered in a timely fashion and should include relevant information about the patient's stay in hospital. ${ }^{2}$ However, the TOC summary is often not present at the first follow-up visit with the $\mathrm{CcP}$, disrupting continuity of care and threatening patient safety. ${ }^{2-4}$ 
New technologies can play an important role in improving communication across the continuum of care. For instance, the use of an electronic transfer of care (e-TOC) communication tool to generate e-TOC summaries may improve the transition process by enhancing the communication among physicians, standardizing content, and promoting the timely delivery of information to the $\mathrm{CcP}^{2-5}$ The e-TOC tool may ultimately lead to better health care delivery through more timely and accurate information transfer.

Yet, the implementation of new health technology such as the e-TOC tool is dependent on its adoption by physicians, as they provide the information needed for the new system's function. Physicians play a large role in the uptake of new technology; resisting the adoption of new technology can influence other physicians and health care providers. To ensure its use by both AcPs and CcPs, it is important to consider the barriers and opportunities that influence the adoption of the e-TOC technology.

Physician experience and characteristics have been identified as some of the many barriers affecting the uptake of new technology. ${ }^{6-8}$ The literature shows that physicians can be reluctant to adopt new innovations based on their perception of the innovation, their beliefs, and the context of the innovation. ${ }^{6,9}$ Reluctance to uptake can also stem from lack of support, time, or incentive to change. ${ }^{7}$ Other factors that are considered by physicians when adopting a new technology have been identified as attitude toward technology, interoperability, technical support, and impact on workflow. ${ }^{10}$ Capturing user feedback and information on factors that specifically influence physicians' adoption of the e-TOC tool will identify deficits in knowledge, leading to solutions to improve adoption of the e-TOC technology. ${ }^{9,11}$

The objective of the present study was to assess the experiences of AcPs and CcPs with the e-TOC communication tool, as well as to identify the barriers and opportunities to the adoption of the new technology at a tertiary care center and nearby community practices in Canada. ${ }^{5,12}$

\section{Materials and methods Study setting and population}

The study was conducted at a Canadian tertiary care and teaching center (Medical Teaching Unit [MTU], Foothills Medical Centre [FMC], Calgary, AB, Canada) as part of a randomized controlled trial (RCT) assessing the efficacy of an e-TOC communication tool. Upon admission, patients were randomly allocated to control (acute care stay was summarized using a traditional dictated TOC summary) or intervention (TOC summary was generated using the newly developed e-TOC communication tool). Once patients were randomized, physicians were alerted about patient allocation, and AcPs generated the TOC summary accordingly, with either traditional dictation or using the e-TOC tool.

The AcPs consisted of attending physicians, resident trainees, and medical students rotating through the MTU. The CcPs were health care providers caring for patients discharged from this unit in the community. This study was approved by the Conjoint Health Research Ethics Board at the University of Calgary.

\section{Description and delivery of intervention}

The e-TOC technology was developed through iterative consultation with stakeholders and patients, leading to the design of a vaporware prototype by a health technology company. The prototype was then modified to fit the existing health information system in Calgary hospitals (Sunrise Clinical Manager) (Figure 1). The structure of the e-TOC summary was different from the traditional and individually dictated TOC summary. There was an emphasis on providing relevant information that was pertinent and complete to the CcPs. For example, changes in medications from admission to discharge as well as follow-up instructions were key issues. The e-TOC tool implementation was accompanied by physician training. Prior to their rotation on the MTU, residents received an information package consisting of printed brochures introducing the e-TOC tool, help sheets, and a training video guiding the trainee through the creation of an e-TOC summary. There was also a formal presentation on the e-TOC tool on the first day of resident rotation (every 4 weeks), and available daily support. ${ }^{5}$ Researchers were available to help unit staff with the e-TOC tool in person Monday to Friday during implementation, and a 24-hour helpline was created to provide additional support. ${ }^{5}$

The e-TOC summary is populated by AcPs, usually residents and medical students, with information such as admission and discharge dates, pertinent laboratory and imaging results as well as medication changes from admission to discharge that are retrieved from the electronic health record. The e-TOC summary also includes patient presentation and history, and $\mathrm{CcP}$ and patient follow-up instructions. Also, a free text box allows for any additional information from the AcPs. Once the e-TOC summary is completed, it is reviewed by the attending physician and automatically uploaded to Alberta Netcare so it is available to CcPs at the time of discharge. Upon discharge, patients also receive a printed copy of the e-TOC summary.

Traditionally, dictated TOC summaries are faxed to CcPs sometime after discharge, and uploaded into individual 


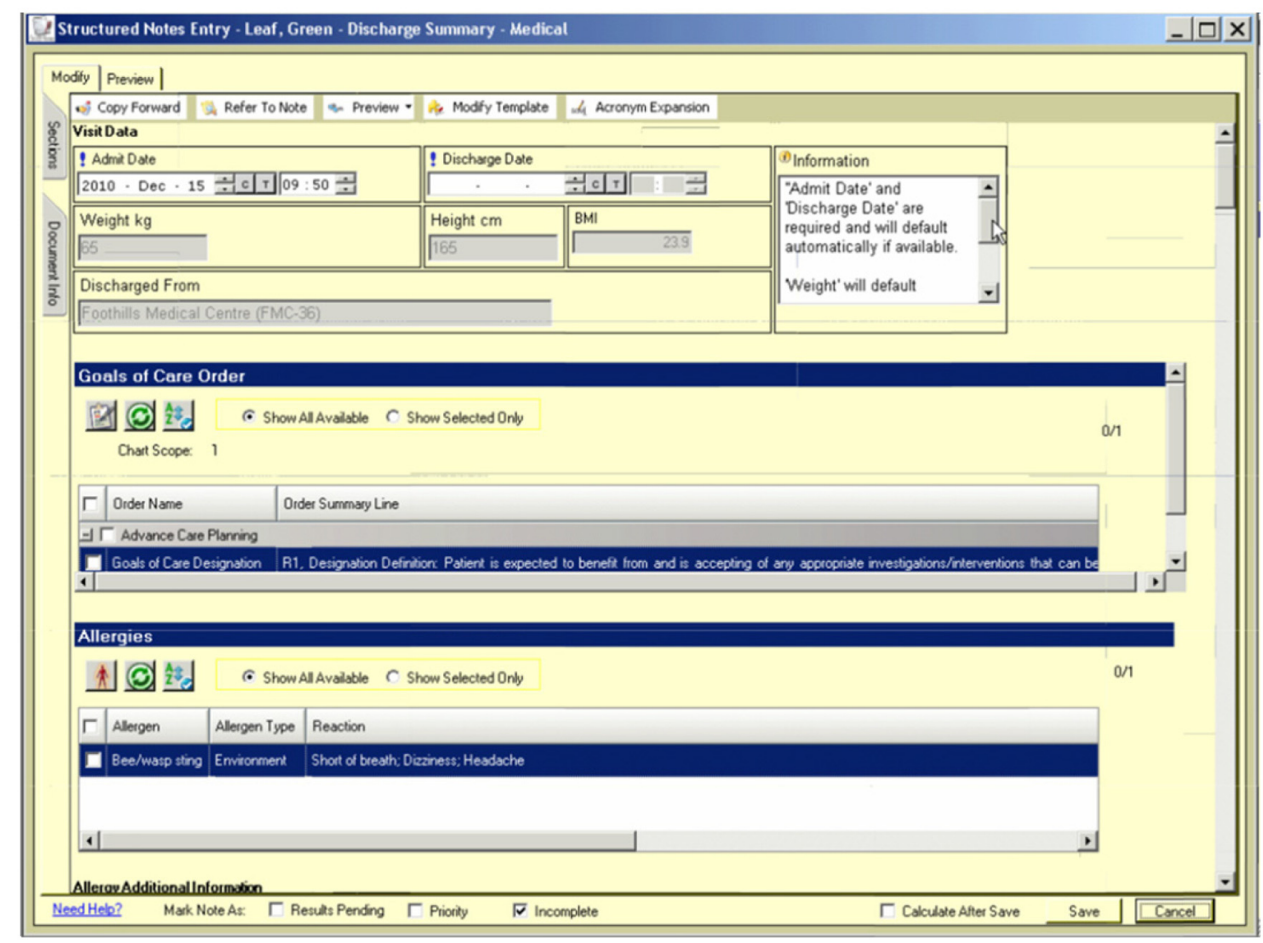

Figure I Screenshot of the electronic transfer of care tool.

electronic health records at the $\mathrm{CcP}$ office, if available. In contrast, the e-TOC summary is communicated via Alberta Netcare (http://www.albertanetcare.ca), where it can be accessed electronically by CcPs in a timely fashion. Netcare is a province-wide health care data repository that is securely accessible for anyone involved in the care of the patient, such as CcPs, nurses, or pharmacists. Since the e-TOC summary is completed electronically, it can be uploaded when a patient is discharged and accessed immediately by their CcP.

\section{Measures of interest}

AcPs and CcPs completed validated surveys assessing their experience with the newly developed e-TOC tool (Tables S1-S3). Free text questions were used to gather general comments from both groups of physicians.

\section{Acute care physician survey}

Acute care surveys were modified from the widely used Questionnaire for User Interaction Satisfaction. ${ }^{6}$ Free text questions were asked at the end of both the pre- and postrotation surveys for general comments on the generation of TOC summaries and the e-TOC tool. Both surveys were centered on AcPs' experiences with the e-TOC tool. Surveys were kept confidential; respondent initials were collected to link pre-and post-rotation surveys; other demographic information was only presented in aggregate.

\section{Pre-rotation}

The pre-rotation survey was conducted at a formal orientation to the MTU, where AcPs were trained on how to use the e-TOC tool. This was done at the beginning of each rotation for every new group of trainees on the MTU at FMC and was collected over ten rotations (4 weeks per rotation). Since the e-TOC tool was already in use on some wards of FMC and some residents had previously rotated through the MTU and had exposure to the e-TOC tool, we included some questions asking AcPs about previous experience with its use. The pre-rotation survey was composed of six questions centered around the generation of TOC summaries, including: length of time to generate a traditional dictated summary versus an e-TOC summary, difficulty in generating an e-TOC summary, and preference of summary generation method, as well as an open-ended question on their views about e-TOC technology (Table S1).

\section{Post-rotation}

Surveys were also completed by AcPs at the end of their rotation on the MTU. We collected AcPs' experiences on the last day of their rotation. The post-rotation survey included seven questions that addressed adoption of the e-TOC tool, such as: number of e-TOC summaries generated, preference for TOC summary generation method, and assessment of a learning curve in the use of the e-TOC tool following their 
rotation on the MTU. A free text box for comments on the tool was also included (Table S2).

\section{Community care physician survey}

CcPs caring for patients admitted to the MTU were contacted post-discharge to complete a brief survey, which was modified from the RCT pilot study ${ }^{5}$ (Table S3). CcP offices were called prior to faxing the survey up to three times within 14 days of the expected follow-up appointment (determined based on the follow-up instructions provided by the AcP in the TOC summary). The physicians were given 5 days between contact attempts to fill in and return the survey by fax. This was done to increase the response rate from physicians. The survey included six questions addressing access to TOC summaries, timely arrival, and quality. Quality of the TOC summary was assessed using van Walraven and Rokosh's scale, addressing: timeliness, organization, completeness, and overall rating of the TOC summary ${ }^{2}$ (Table S3). At the end of the survey, a free text box allowed CcPs to provide their views.

\section{Data analysis}

Units of analysis were individual physicians. Data from the surveys were analyzed using mixed methods. Quantitative data were analyzed descriptively using SPSS software. All continuous quantitative data, such as time to complete TOC summaries, were reported as means (with standard deviations) and Student's $t$-tests were conducted to compare the quality of the TOC summaries between the two groups. Qualitative data obtained from the free text questions on both surveys were analyzed thematically. ${ }^{13}$

\section{Results}

\section{Quantitative results}

\section{Acute care physicians}

Pre- and post-rotation surveys were collected for ten rotations of residents from March 2013 until December 2014, when the final rotation of AcPs participating in the RCT was completed. The AcPs were young females (43.5\%) specializing in internal medicine $(37.7 \%)$ who graduated between 2000-2014 (75.4\%; Table 1).

\section{Pre-rotation}

Out of the 138 AcPs surveyed, 14 of them took an average (standard deviation) of 22.14 (15.98) minutes and a maximum of 60 minutes to complete the dictated summary; only 63 AcPs had previous exposure to the tool and rated their preference of e-TOC summaries over traditionally dictated TOC summaries as eight out of ten (on a scale of $1-10 ; 1=$ prefer dictation; $10=$ prefer electronic).
Table I AcPs' characteristics $(\mathrm{N}=\mid 38)$

\begin{tabular}{ll}
\hline & $\mathbf{N}(\%)$ \\
\hline Age (years)* & \\
$20-30$ & $102(73.9)$ \\
$3 \mid-40$ & $24(17.4)$ \\
$4 I-50$ & $3(2.2)$ \\
$>50$ & $1(0.7)$ \\
Sex & \\
$\quad$ Female & $60(43.5)$ \\
Specialty & \\
Internal medicine & $52(37.7)$ \\
Family medicine & $21(15.2)$ \\
$\quad$ Clerk & $19(13.8)$ \\
Other** & $46(33.3)$ \\
Trainee & \\
$\quad$ Yes & $5 I(36.9)$ \\
Years since medical school graduation*** & \\
$\quad<2000$ & $3(2.2)$ \\
$2000-20 \mid 4$ & $104(75.4)$ \\
\hline
\end{tabular}

Notes: *Eight AcPs did not provide age; **other consists of dermatology, otolaryngology, and neurology; ***3। AcPs did not provide years since graduation. Abbreviation: AcP, acute care physician.

\section{Post-rotation}

Post-rotation on the MTU, AcPs had completed an average (standard deviation) of 6.3 (7.8) e-TOC summaries per physician, which each took an average of 37.35 (23.12) minutes and a maximum of 45 minutes to complete. It took an average of 2.35 (2.12) days for the AcPs to adjust to and become familiarized with the e-TOC tool. The AcPs did not find it very difficult to complete the e-TOC summary, median (range), $8.00(6.00-9.00)$ on a 10-point scale with $1=$ very difficult and $10=$ very easy. AcPs also preferred the e-TOC summary to the traditional summary $9.00(4.50-10.00)$ on a 10 -point scale with $1=$ prefer dictation and $10=$ prefer electronic.

\section{Community care physicians}

The surveys from CcPs were collected from the beginning of June 2013 until the end of January 2014, 1 month after the RCT was completed.

In contrast to the AcPs, the $\mathrm{CcP}$ cohort was older, with $49.4 \%$ over the age of 50 years. Seventy-two percent of the CcPs had the TOC summary present at the time of the first follow-up visit and 50\% accessed it by fax. Although $91 \%$ of the physicians or their nurses had access to Netcare, only $14 \%$ used Netcare to access the discharge summary. CcPs indicated that they accessed the TOC summary either before, during or after the visit, where $20 \%$ said they seldom accessed the TOC summary before the visit, 19\% said they seldom accessed it during the visit, and 24\% said they access it very often after the visit. The CcPs found the TOC summaries to be useful in terms of patient care, mean (standard deviation) 9.0 (1.6). CcPs rated the quality of 67 dictated TOC and 80 e-TOC summaries. The quality of the 
TOC summaries was assessed based on the categories of organization, completeness, pertinence, and overall rating (Table 2). There was no difference in quality between the e-TOC and traditional summaries (Table 2).

\section{Qualitative results}

Thematic analyses revealed barriers and opportunities encountered by physicians toward the adoption of the e-TOC tool. Barriers were defined as usability issues and difficulties encountered that hindered user satisfaction. Opportunities were discerned from positive feedback given by AcPs and CcPs. The e-TOC tool was assessed in the post-rotation survey (Table 3 ).

\section{Acute care physicians}

Three sub-themes were identified in the analysis of AcPs' comments. First, time was reported on in terms of convenience, efficiency, and efficacy in sharing information with teams.

\section{Convenience}

Better than dictation $[\ldots]$ because you can start on it earlier.

Electronic summary allows for day-to-day addition and handover for subsequent teams.

Advantage is that you can begin at any time and provide updates - easier for team members to complete.

\section{Efficiency}

If long stay then electronic is efficient, time saving. Very convenient especially because it's easily started and stopped.

However, some AcPs did note that the speed of completion was lacking:

$[\ldots]$ how long it takes to complete.

\section{Efficacy}

Electronic allows you to continually enter information starting on admission, and not have to do it all on discharge when dictating.

Table 2 CcP ratings of quality based on completeness, pertinence, organization, and overall for electronic and traditional TOC summaries as means (SD)

\begin{tabular}{|c|c|c|c|}
\hline $\begin{array}{l}\text { Quality } \\
(0=\text { worst, } \\
\text { 1 } 0=\text { best })\end{array}$ & $\begin{array}{l}\text { e-TOC } \\
\text { Summary } \\
(\mathbf{N}=\mathbf{8 0})\end{array}$ & $\begin{array}{l}\text { Traditional } \\
\text { TOC summary } \\
(\mathrm{N}=67)\end{array}$ & $t$-tests \\
\hline & $\overline{\text { Mean (SD) }}$ & Mean (SD) & $P$-value \\
\hline Completeness & $8.55(1.16)$ & $8.54(1.3 \mathrm{I})$ & 0.95 \\
\hline Pertinence & $8.44(1.47)$ & 8.55 (1.44) & 0.63 \\
\hline Organization & 8.15 (1.7I) & $8.60(1.44)$ & 0.87 \\
\hline Overall rating & $8.28(1.48)$ & $8.55(1.45)$ & 0.26 \\
\hline
\end{tabular}

[...] good for handover or multiple people working on summary, continually enter info good for start any time, pick up and leave it whenever, more organized with electronic.

The ease with which physicians could use the program was highlighted:

Easier to use.

Easy to edit.

Some AcPs noted areas for improving user satisfaction:

Electronic $\mathrm{d} / \mathrm{c}$ is cluttered.

Formatting still issue - medications integrated into

SCM d/c summary would be helpful.

The barriers identified support the quantitative results that it took more time for the AcPs to generate the e-TOC summary compared to the dictated TOC summary, and that it took time to adjust to the e-TOC tool. In parallel, opportunities were identified with adoption of the e-TOC tool such as improved continuity of care and more efficient workflow because the e-TOC summary could be started from admission (Table 3 ).

\section{Community care physicians}

The CcPs were asked to provide any comments or feedback at the end of the survey (Table S3). The main themes identified from this feedback were related to access, timeliness, quality of information of the TOC summaries and continuity of care. The major barrier to adoption is systematic in nature: accessing the TOC summary through Netcare. This is also seen in the quantitative results, where few of the CcPs accessed the TOC summary via Netcare.

\section{Accessing the summary through Netcare}

Many of the CcPs attempted to use Netcare, but encountered difficulties:

Unable to access Netcare - we tried.

Discharge summaries are usually not available on Netcare $[\ldots]$

\section{Timeliness}

Timeliness was correlated to accessing the summary via Netcare. Faxes were preferred for their promptness:

I prefer discharge summaries faxed to me. Netcare is great but the summary might not be there yet when we look and it is very time consuming to keep checking if it has been posted. 
Table 3 Qualitative results from acute care and community care physicians

\begin{tabular}{|c|c|c|}
\hline Physicians' themes & Barriers & Opportunities \\
\hline \multicolumn{3}{|l|}{ Acute care } \\
\hline I. Timeliness & $\begin{array}{l}\text { "Slow and tedious process - takes physicians } \\
\text { away from care duties and spend more time as } \\
\text { stenographer - poor economics." }\end{array}$ & "Efficient, time saving." \\
\hline 2. Usability & "Electronic discharge is difficult to navigate." & $\begin{array}{l}\text { "Easy to use, use to see what is written so that I may } \\
\text { provide quick corrections." }\end{array}$ \\
\hline 3. Presentation & $\begin{array}{l}\text { "When reading the summary it's far too cluttered with } \\
\text { unnecessary detail compared to the dictated ones." }\end{array}$ & $\begin{array}{l}\text { "Less mistakes - everything laid out in front of me, ie, } \\
\text { won't forget anything." }\end{array}$ \\
\hline \multicolumn{3}{|l|}{ Community care } \\
\hline I. Access & $\begin{array}{l}\text { "Access is not always available as Netcare website is } \\
\text { unreliable and slow and X-rays are not always there." }\end{array}$ & "Very helpful to have discharge summaries." \\
\hline 2. Timeliness & $\begin{array}{l}\text { "In the summary received } 3 \text { weeks after discharge, it } \\
\text { asked me to check on her in a week }[\ldots] . " \\
\text { "Often wait very long before discharge summary } \\
\text { available." }\end{array}$ & $\begin{array}{l}\text { "Timeliness and completeness revolutionary } \\
\text { improvement over earlier pancreatitis admission." } \\
\text { "This patient had two admissions; within a few days we } \\
\text { received summaries for both in good time, thank you." }\end{array}$ \\
\hline $\begin{array}{l}\text { 3. Quality of information } \\
\text { and continuity of care }\end{array}$ & $\begin{array}{l}\text { "[...] no note from her social worker was included } \\
\text { in the summary and no follow-up from social worker } \\
\text { was done after patient was discharged. She presented } \\
\text { to my office in ++distress [...]." } \\
\text { "Summary didn't provide consultant notes which } \\
\text { would have been very useful." }\end{array}$ & $\begin{array}{l}\text { "Very helpful with ongoing management. Thanks!" } \\
\text { "Appreciate the summaries - very legible and useful." } \\
\text { "Keep it up for continuity of patient care, hospital stay } \\
\text { and f/u of medications." }\end{array}$ \\
\hline
\end{tabular}

Abbreviation: f/u, follow-up.

Faxes serve multiple purposes to CcPs - this includes alerting them that their patients have been discharged:

I really like these summaries. Access on Netcare is good but for me fax is better as it alerts me that my patient[s] has been discharged.

However, some CcPs identified benefits of the e-TOC summaries as improved timeliness and ongoing patient care:

Timeliness and completeness revolutionary improvement $[\ldots]$

\section{Quality of information}

Quality of information was lacking for CcPs, who require more context to treat their patients.

Summary didn't provide consultant notes which would have been very useful.

I would have liked more detail about managing her condition $[\ldots]$

\section{Continuity of care}

Continuity of care refers to properly addressing the patients' needs and referrals:

The patient had a lower GI bleed [...] no follow-up was planned [...].

\section{Discussion}

While an RCT was conducted assessing the efficacy of the e-TOC communication tool, we assessed physicians' views and identified barriers and opportunities toward the adoption of the e-TOC tool. Our qualitative results corroborated the quantitative results. In general, the newly developed e-TOC tool was well-received by both groups of physicians. The AcPs did not find it difficult to generate the e-TOC summaries, nor did it take a long time to generate them. AcPs preferred the e-TOC summary to the traditional TOC summary. Most of the AcPs did find that there was a learning curve to the e-TOC tool and that it took on average a couple of days to adjust to the new technology.

Themes that emerged from qualitative data addressing barriers to adoption included timeliness, usability, access, and quality of information. Opportunities identified by the AcPs were that it facilitated continuity of care and helped ensure improved patient safety. The CcPs rated the quality of the e-TOC summary highly but identified access to the e-TOC summaries via Netcare as a major barrier to adoption. Timely delivery of the e-TOC summary and its usefulness for ongoing patient care were identified as major opportunities. However, overall $\mathrm{CcP}$ satisfaction with the quality of the e-TOC summaries remained high, and was not significantly different from scores for traditional TOC summaries. 
The notion of reluctance for adoption of new technologies in medicine is pervasive in the literature. ${ }^{69}$ A variety of reasons have been proposed to explain the slow uptake of new technology by physicians, including interruption of traditional practices, the necessity for more learning, and a lack of organization and time required for implementation. ${ }^{6}$ The literature suggests that lack of organization includes both the training and infrastructure necessary to support the new technology. ${ }^{6}$ The time it takes to adopt new technology is a factor that influences whether physicians will accept the technology. ${ }^{9,10}$ Although we did not ask AcPs about the factors of organization that could impact uptake, the time to adjust to the e-TOC tool and the time to generate the e-TOC summaries as reported by the AcPs indicate that time is a factor that could affect the uptake of the e-TOC technology. The literature proposes that this could be due to the necessity for more training or the interruption of traditional practices. ${ }^{6}$ A potential solution to mitigate slow uptake is education, particularly formal training, which has been shown to facilitate the uptake of technology by physicians by making their use of technology more efficient. ${ }^{11}$ The addition of a learning component provides an opportunity for improvement in the time burden to generate e-TOC summaries and the learning curve associated with the electronic tool..$^{11,14}$

Demographic characteristics such as age of physicians has been identified as an indirect reason for reluctance to adopt new technology, whereas issues such as anxiety around computers and experience with computers may have a direct negative influence on the adoption of new technology. ${ }^{6,10}$ Our study did not directly address anxiety around computers, although the reluctance to adopt new technology is seen in how the CcPs access the e-TOC summary. Although Netcare is available to most physicians or their nurses in our study, fax was still used more often to access the TOC summary. The qualitative results indicate that there was difficulty accessing the e-TOC summary via Netcare due to unreliability and slow access to the Netcare system. The literature proposes that lack of organization, including infrastructure to support the technology, can create reluctance in the uptake of new technology. ${ }^{6}$ It has been shown in the context of electronic health record implementation that the use of incentives can facilitate the uptake of new technology for physicians. ${ }^{9}$ In order for the e-TOC tool to have the greatest impact, CcPs need to be able to access the summaries in a timely manner via Netcare; therefore, the issues with reliability and access need to be addressed. Overall, $\mathrm{CcP}$ satisfaction with the e-TOC summaries and the post-rotation results for the AcPs showing a preference for the e-TOC tool over the traditional dictation method indicated that the implementation of the e-TOC tool was largely successful. Education on the generation of TOC summaries could be used to address the identified issues, including missing information, ${ }^{14}$ and also improve uptake of the technology by increasing physician confidence and efficiency in the use of the e-TOC tool technology. ${ }^{14}$ The addition of a learning component provides an opportunity for improvement in the time burden of generating e-TOC summaries and the learning curve associated with the electronic tool for AcPs, thereby facilitating widespread uptake and adoption of the e-TOC tool by physicians. ${ }^{11,14} \mathrm{~A}$ formalized education module could be developed by Alberta Health Services to be delivered to physicians working in hospitals with the tool to ensure sustained and effective use of the tool. In addition, work on the Netcare platform is needed, either to improve efficient access to the system or to educate $\mathrm{CcPs}$ on better Netcare use.

Our study captured $\mathrm{AcP}$ and $\mathrm{CcP}$ perspectives on the adoption of new technology specific to hospital discharge communication. These perspectives are valuable for finding ways to facilitate the adoption of the e-TOC technology and also contribute knowledge about the barriers and facilitators to uptake of new electronic technology by physicians.

There were limitations to our study that need to be considered. The limited ability of this study to clearly draw the conclusion that the e-TOC tool was better in terms of providing high-quality summaries may be due to the study design and the contamination issues attached to it. Physicians were not the unit of randomization; they were exposed to both types of summaries (dictated and electronically generated). This contamination between the two modes of summary generation has likely clouded the final results. Also, our study was conducted on an MTU at a tertiary care center, so these results may not be generalizable to other types of facilities or other locations. There is a time lag between the collection of data from AcPs and CcPs. We started collecting AcPs views prior to CcPs due to team human resources limitations. Our intention was to collect physician experiences and present them in an aggregate form to the reader. A potential recall bias also exists, as surveys were not conducted at the time of TOC summary generation or immediately following a follow-up visit with a patient (for CcPs).

Exploration of formal training opportunities to facilitate the uptake of new technology by physicians should be explored to mitigate the time burden and lack of organization resultant from this process. The learning component by physicians may be of interest to other innovators considering the 
uptake of new technology in the health care field and should be investigated further. The way in which CcPs access the TOC summary should be further investigated and considered when implementing a new technology for physicians.

\section{Acknowledgments}

The authors would like to thank the physicians for their involvement in the study. We would also like to thank Barbara Okoniewska, Aida Raissi, Wrechelle Ocampo, Nancy Clayden, and Murtaza Dahodwala for their assistance in distributing the acute care physician survey. Furthermore, we would like to acknowledge the reviewers for their critical feedback.

\section{Disclosure}

The authors report no conflicts of interest in this work.

\section{References}

1. Kripalani S, Jackson AT, Schnipper JL, Coleman EA. Promoting effective transitions of care at hospital discharge: a review of key issues for hospitalists. J Hosp Med. 2007;2(5):314-323.

2. van Walraven $\mathrm{C}$, Rokosh $\mathrm{E}$. What is necessary for high-quality discharge summaries? Am J Med Qual. 1999;14(4):160-169.

3. van Walraven C, Laupacis A, Seth R, Wells G. Dictated versus databasegenerated discharge summaries: a randomized clinical trial. CMAJ. 1999;160(3):319-326.
4. Chan S, Maurice AP, Pollard CW, Ayre SJ, Walters DL, Ward HE. Improving the efficiency of discharge summary completion by linking to preexisting patient information database. BMJ Qual Improv Report. 2014;3(1):1-4.

5. Santana MJ, Holroyd-Leduc J, Flemons WW, et al. The seamless transfer of care: a pilot study addressing the usability of an electronic transfer of care communication tool. Am J Med Qual. Epub September 19, 2013.

6. Dansky KH, Gamm LD, Vasey JJ, Barsukiewicz CK. Electronic medical records: are physicians ready? J Healthc Manag. 1999;44(6):440-455; discussion 454-455.

7. Berwick DM. Disseminating innovation in health care. JAMA. 2003; 289(15):1969-1975.

8. Miller RH, Sim I. Physicians' use of electronic medical records: barriers and solutions. Health Aff (Millwood). 2004;23(2):116-126.

9. Shank N. Behavioral health providers' beliefs about health information exchange: a statewide survey. J Am Med Inform Assoc. 2012;19(4): 562-569.

10. Castillo VH, Martinez-García AI, Pulido JRG. A knowledge-based taxonomy of critical factors for adopting electronic health record systems by physicians: a systematic literature review. BMC Med Inform Decis. 2010;10:60.

11. Alderton M, Callen J. Are general practitioners satisfied with electronic discharge summaries? HIM J. 2007;36(1):7-12.

12. Okoniewska BM, Santana MJ, Holroyd-Leduc J, et al. The Seamless Transfer-of-Care Protocol: a randomized controlled trial assessing the efficacy of an electronic transfer-of-care communication tool. BMC Health Serv Res. 2012;12:414.

13. Guest G. Applied Thematic Analysis. Thousand Oaks, CA: Sage Publications; 2012:11.

14. Myers JS, Jaipaul CK, Kogan JR, Krekun S, Bellini LM, Shea JA. Are discharge summaries teachable? The effects of a discharge summary curriculum on the quality of discharge summaries in an internal medicine residency program. Acad Med. 2006;81(Suppl 10):S5-S8. 


\section{Supplementary materials}

Table SI Users experiences with the transfer of care tool- pre-rotation

\section{Users Experiences with the Transfer of Care Tool - Pre-rotation}

Your initials (including middle initial) *for linkage purposes only, answers will remain anonymous

Physician characteristics

$\begin{array}{lccc}\text { I. Age (circle) } & 20-30 & 3 I-40 & 4 I-50\end{array} \quad>50$

5. Years on staff

6. Year of medical school graduation

\section{Pre-rotation questionnaire}

I. On average, how long does it take you to complete a dictated discharge summary? minutes

2. Have you used the electronic discharge tool before?

Yes No

If yes, please continue to the next question. If no, please skip to question 7.

3. Approximately how many discharges have you completed with the electronic tool?

4. On average, how long does it take you to complete an electronic discharge summary? minutes

5. How difficult is it to complete the electronic discharge summary?

Very difficult I 23456789 I0 Very easy

6. Please indicate which discharge summary method you prefer: Prefer dictation I 2345678910 Prefer electronic

7. Please provide any comments about what you would like to see in an electronic discharge:

Table S2 Seamless transfer of care tool survey - post-rotation

Seamless Transfer of Care Tool Survey - Post-rotation

Your initials (including middle initial) *for linkage purposes only, answers will remain anonymous

Post-rotation questionnaire

I. Approximately how many discharges have you completed with the electronic tool?

2. On average, how long does it take you to complete an electronic discharge summary? minutes

3. How difficult is it to complete the electronic discharge summary? Please circle: Very difficult I 2345678910 Very easy

4. Please indicate which discharge summary method you prefer. Please circle: Prefer dictation I 2345678910 Prefer electronic

5. Did you find there was a learning curve with using the electronic tool? Yes No

a. If yes, how long did it take you to feel comfortable using the tool? days

6. Please provide any comments about the electronic discharge tool: 
Table S3 Physician perception survey

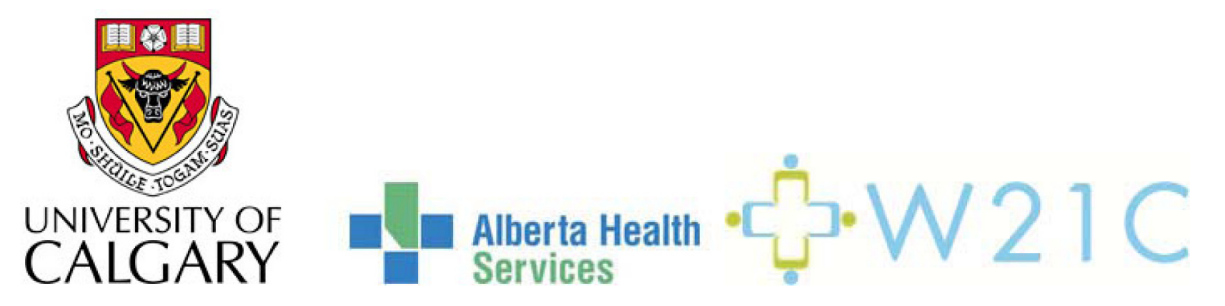

\section{Physician Perception Survey:}

\section{Transfer of Care Summaries}

\section{Physician characteristics}

Age (circle):
20-30
$31-40$
$4 I-50$
$>50$

Receiving physician survey

I. Have we correctly identified you as a health care provider for this patient?

$\square$ YES

$\square$ NO (if no, please stop here and return survey by fax)

2. Did you have the discharge summary for this patient when you saw them for their first visit to your office post-hospitalization?

$\square$ Yes

$\square$ No

$\square$ N/A - patient has not had follow-up visit (if N/A, skip to question 4)

3. How did you access the hospital discharge summary for this patient?

$\square$ Netcare

$\square$ Fax

$\square$ Mail

$\square$ Patient delivered

$\square$ N/A - did not access discharge summary

5. If you had the discharge summary prior to or during the patient visit, how useful was it in terms of patient care? Not at all useful I 23456789 I0 Very useful

6. Do you or your nurse have access to Netcare?

$\square$ YES

$\square$ NO (if no, skip to question 8)

7. If YES, how often do you or your nurse access the discharge summary on Netcare?

Before patient visit Seldom I 2345678910 Very often

During patient visit Seldom I 2345678910 Very often

After patient visit Seldom I 2345678910 Very often

8. What is your preferred method for receiving discharge information?

$\square$ Patient-delivered

$\square$ Faxed

$\square$ Mailed

$\square$ Web-based (Netcare) 
Table S3 (Continued)

Quality of discharge summary

Please rate the quality of information included in the discharge summary. Scale rates each component from 0 (worst) to I0 (best).

Criteria

Completeness (was all information included?)

Pertinence (was all included information relevant?)

Organization of information in summary

Overall rating

Please provide any comments or feedback:
Scale (circle)

$\begin{array}{lllllllllll}0 & 1 & 2 & 3 & 4 & 5 & 6 & 7 & 8 & 9 & 10\end{array}$

$\begin{array}{llllllllllll}0 & 1 & 2 & 3 & 4 & 5 & 6 & 7 & 8 & 9 & 10\end{array}$

$\begin{array}{llllllllllll}0 & 1 & 2 & 3 & 4 & 5 & 6 & 7 & 8 & 9 & 10\end{array}$

$\begin{array}{lllllllllll}0 & 1 & 2 & 3 & 4 & 5 & 6 & 7 & 8 & 9 & 10\end{array}$

Thank you very much for your time!

Abbreviation: N/A, not applicable.

\section{Publish your work in this journal}

The Journal of Multidisciplinary Healthcare is an international, peerreviewed open-access journal that aims to represent and publish research in healthcare areas delivered by practitioners of different disciplines. This includes studies and reviews conducted by multidisciplinary teams as well as research which evaluates the results or conduct of such teams or

\section{Dovepress}

healthcare processes in general. The journal covers a wide range of areas and welcomes submissions from practitioners at all levels, from all over the world. The manuscript management system is completely online and includes a very quick and fair peer-review system. Visit http://www.dovepress.com/testimonials.php to read real quotes from published authors.

\footnotetext{
Submit your manuscript here: http://www.dovepress.com/journal-of-multidisciplinary-healthcare-journal
} 